\title{
Leaving-But Not Yet Left: A Rejection of the Perception 'God's Waiting Room' in Favour of Humanistic Residential Aged Care
}

\author{
Terence Seedsman ${ }^{1} \&$ Belinda Seedsman ${ }^{2}$ \\ ${ }^{1}$ Victoria University/Melbourne-Australia, College of Sport and Exercise Science, Melbourne, Australia \\ ${ }^{2}$ Nurse practitioner Frankston-Mornington Peninsula, Frankston, Australia \\ Correspondence: Dr. Terence Seedsman, Emeritus Professor, Victoria University/Melbourne-Australia, College \\ of Sport and Exercise Science, Melbourne, Victoria, Australia.
}

Received: July 27, 2019

Accepted: August 31, 2019

Online Published: September 5, 2019

doi:10.20849/ijsn.v4i3.625

URL: https://doi.org/10.20849/ijsn.v4i3.625

\begin{abstract}
Background: Healthcare systems worldwide will be increasingly challenged to meet the complex needs of aging populations. In particular, the operation of residential aged care facilities will require improved surveillance and monitoring to ensure that quality assurance systems are in place that support holistic and humane care of all aged care residents.

Objectives: To undertake a selected literature search including a focus on Australian based case studies with the intention of a) developing a philosophical orientation towards improving awareness and understandings among policy makers and residential aged care workers to transform residential aged care into an environment that protects human rights b) drawing attention to how the adoption of an attitude that sees aged care recipients as having left while still living has the potential to create a minimalist approach to care and c) highlighting the need for emotionally intelligent leadership as a core component for establishing, facilitating and coordinating the delivery of quality assurance systems in residential aged care.
\end{abstract}

Methodology: This is not a quantitative study but one essentially focused on offering a professional perspective on residential aged care resulting from a reading of selected literature and the combined existential experiences and understandings of both authors. The preceding approach provided the groundwork for presenting a case for honouring human rights in tune with the adoption of a substantive philosophy for the overall operation of residential age care facilities.

Conclusion: While entry into residential aged care can be seen to represent the final chapter in an older person's life, there remains the ever-present mandate for formal caregivers to not stray from the moral obligations associated with 'ethical caregiving'.

Keywords: dementia, duty of care, person centered care, personhood, missed calls, structured dependency

\section{Introduction}

There is no doubt that in Australia and throughout the wider world that population aging will place an unprecedented demand for aged care services and programs due to older people living longer. However, we need to be mindful of the fact that "as more people live to older ages, the prevalence of chronic illness increases markedly" (Productivity Commission, 2008, p. 44). How tragic is the metaphorical view taken by many that once older people are placed in a nursing home they are in essence allocated a space in 'God's Waiting Room' biding their time prior to passing away. Gawande (2015) provides a dose of contemporary reality in reminding us "old age and infirmity have gone from being a shared, multigenerational responsibility to a more or less private state-something experienced largely alone or with the aid of doctors and institutions" (p. 17). Unfortunately, treatment regimes in residential aged care settings can be such that older residents are assumed to have already left even though the end of life is yet to come. While this false assumption is not ethically acceptable, it nevertheless represents an all too convenient opportunity for adopting a callous easing of responsibility leading to a minimalist approach by those aged care workers who have no sense of providing an enduring and genuine commitment to a duty of care. It is not surprising, therefore, that in some instances there emerges a type of consciousness among some aged care workers whereby they simply embrace the preceding viewpoint which a) governs their attitudes and actions and b) facilitates the development and implementation of a narrow and 
confined operational framework, thereby reducing the opportunity for true human support and connection. It might be said, that interpersonal relationships between staff and aged care residents are often compromised when staff "are biased against their looks, their smells, their idiosyncratic habits" (Hillman, 1999, p. 163).

In terms of navigating institutional care for the aged it must be understood that difficulties arise from the outset when quality care competes with inflexible management practices, bureaucratic policies and profit orientations (see Allard, 2016). Brennan et al. (2012) in addressing cost saving measures in residential aged care proffer the following argument "changes in skills mix in Residential Aged Care should be understood in the context of cost savings made on the basis of employment of less qualified staff" (cited in Willis et al; 2016, p. 101). Unfortunately, entry into a residential aged care facility places the older person into what amounts to living in a 'structured dependency' life space (Grenier \& Phillipson, 2014; Ray, 2014). When an aged care recipient creates problems and / or is displaying chronic health related conditions the approach more often taken than not is to resort to medication. Ireland (1996) argues "The cornerstone principle for rational medication use in the elderly population should be to improve the mental and / or physical quality of life of the individual" (p. 309). When an older person is in receipt of medication(s) and no discernible improvements are recorded then any continuation of the chemical treatment should be seriously questioned. Ireland makes the point "Simply because no apparent detriment has been identified while taking a chemical does not mean the chemical is benefitting the user" ( $p$. 309). Use of medications by aged care staff as a means of 'quick fixing' behavioural problems or health related conditions can overtime result in a series of medication errors stemming from poly-medication (Koper et al; 2013) with dire consequences for the quality of life of an aged care recipient (see Hillen, Vitry \& Caughey, 2015). All too often, staff with little or no skills to manage difficult dementia patients resort to the administration of anti-psychotic drugs sometimes without consultation with immediate family members or assigned guardians.

We as a modern society need to undertake an honest and rigorous appraisal of residential aged care even to the point of confronting the disturbing possibility that life is seen as having little value in 'God's Waiting Room'. There is of course the indisputable and moral obligation to uphold the safety, respect, dignity and support of the aged made vulnerable by the passage of time. Indeed, and without revocation "We impede the evolution and the development of the human species if we neglect the aged" (Hillman, 1999, p. 190). Ray (2014) offers a valuable commentary applicable to those residential aged care workers who adopt a restricted approach to care underpinned by a practice whereby "priority is given to a narrative of dysfunction, focussed at the level of the individual 'at risk' and characterised by a language of pessimism along with limited attention to the impact of structural forces on older people" (p. 144). Such an approach, is most unlikely to generate concern or empathetic understanding of the 'human condition' leading all too often to a) the generation of negative outcomes from 'structured dependency' and b) neglect of human rights. Townsend (2007) in his concern for the adoption of human rights to be embedded in all matters affecting older people, particularly on problems and issues surrounding dependency, concluded:

Human rights instruments offer hope of breaking down blanket discrimination and of using resources more appropriately, and more generously, according to severity of need. But investment in human rights is not only a moral and quasi-legal salvation from things that are going depressingly wrong. Used best, human rights offer a framework of thought and planning [for] the $21^{\text {st }}$ century that enables society to take a fresh, and more hopeful, direction. (p. 43)

\section{The Way Forward: 'We' Rather Than 'Us' and 'Them'}

Perhaps, it is timely for all of us to fully understand that increased longevity means that our chances or those of immediate or close family members requiring residential aged care in later life have increased markedly. Avorn (1986) draws our attention to the realty that "It has often been noted that the aged comprise the one minority group that nearly all of us will enter" (p. 224). It might be said that 'In one way or another, we are all in this together'. Maddox (1992) in a creative use of an old road safety slogan provides a timely and insightful warning to all and sundry "Drive carefully, the slogan went, the life you save may be your own. As we think about the future of aging, think carefully about the future you imagine and propose to construct, the future you construct may be your own" (p. 66). The present authors hold fast to the belief that there is a need for more genuine connection between staff and residents in aged care facilities. Staff who do not have the commitment, energy or time to do so, should not be working with and for elderly residents. Brown (2013) makes the telling and sad commentary "When we treat people as objects, we dehumanize them. We do something really terrible to their souls and our own" (p. 150). The classic text written by the Austrian philosopher Martin Buber "I and Thou" highlighted that every human life finds its essential meaningfulness in relationships. Buber (2000) in the English translation of his original text articulates a differentiation between what he terms as the 'I-it' relationship and the 'I-you' relationship. Brown (2013) provides an explanatory note on Buber's philosophy which contains an 
important perspective for aged care workers "An I-it relationship is basically what we create when we are in transactions with people whom we treat like objects-people who are simply there to serve us or complete a task. I-you relationships are characterized by human connection and empathy" (p. 150).

Unfortunately, it seems that society as a whole is not giving sufficient attention to the demographic transition that is currently underway resulting from a decline in fertility rates and assisted by advances in medical technology and innovation alongside public health policy initiatives. The words of De Beauvoir (1977) some four decades ago appear relevant more so than ever" Nothing should be more expected than old age: nothing is more unforeseen" (p. 10). We might all reflect for a moment on the proverb 'There but for the grace of God go I'. In other words, aging is a process common to all human beings, and as such, nobody can predict what future circumstances in later life will lead some of us to need the support of residential aged care. Jecker (1993) provides a sobering perspective relevant to all of us "it is foolish to forget that all of us undergo frailty and dependence as much, or more, than we enjoy vigor and independence" (p. 287). According to Gawande (2015) the failure to build a quality based and sustainable aged care system occurs because "We put off dealing with the adaptations that we need to make as a society. And we blind ourselves to the opportunities that exist to change the individual experience of aging for the better" (p. 35). A recent case in point is illustrated by a litany of significant failures of care that were found to be in contravention of the Mental Health Act 2009 at the Oakden Older Persons Mental Health Service in the South Australian city of Adelaide. Oakden is a statewide institution located in Northern Adelaide established for the specific purpose of providing care and accommodation to older people with complex mental health needs, where living in the community or in a mainstream residential aged care facility has been deemed to be no longer a realistic or sustainable option. The Oakden Report prepared by Groves et al. (2017) shows what can go horribly wrong when actions are not duly taken to correct hard core evidence of abuse and neglect. Groves and his fellow colleagues made the following observation as part of their overall review findings "There seemed to be a poor understanding among staff, as evidenced by the case files, in regards; modern falls mitigation, the use of trauma informed principles to avoid the use of restrictive practices, wound care, pain management, assistance with activities of daily living, management of wandering, the use of sensory modulation, management of agitation and arousal, management of disturbed sleep-wake cycles and the nursing management of common medical problems including how to undertake common medical procedures" (p. 80). The South Australian Government (2017) in a subsequent response to The Oakden Report indicated that the significant and unacceptable failures of aged care were due to not providing "the right care, at the right time, from the right team" (p. 3).

Baldwin et al. (2015) argue that residential aged care in Australia should be restructured in accordance with the emerging evidence based research that supports the need for transformational change. Recognition must be given to the fact that throughout the life course we are all vulnerable in one way or another. It seems appropriate to make a clarion call: Beware - you may inherit an aged care system that denies you and your family access to quality based holistic care due to opportunities not taken to demand appropriate actions to facilitate and coordinate the continuous enhancement of the aged care sector. Human services professionals serving the needs of older people should take time to reflect that prior to entering a residential care facility that each individual has a unique past and that they should not now be viewed solely within the context of a person with health and / or behavioural problems. Indeed, it is only a short step from focusing on problems of the aged to the next step whereby the focus is one of increasing negativity leading to the belief that when an older person enters residential aged care that the separation is mutually beneficial for both the older individual and society. The demarcation of the citizenry into an 'us' and 'them' with the latter taken to refer to people assigned to life in a residential aged care facility can set in motion the inhumane process whereby aged care recipients become 'invisible' to the rest of society. As human beings, it is perhaps useful to reflect on the notion of our 'shared vulnerability' as highlighted by The President's Council on Bioethics (2005): We are all vulnerable to the deprivation of illness or injury and the limitation of mortality, and thus we all have a personal interest in ensuring that needy persons are treated equally and adequately. (p. 105)

For Gawande (2015) the overall approach to aged care is not, as yet, a cause for celebration as "Life for older people can be better than it is today" (p. 53). Any serious attempt to offer quality aged care in residential settings must first challenge and remove the inertia that impacts a number of key decision makers who take advantage of the notion 'Out of sight, out of mind'.

The following outdated and controversial viewpoint expressed by Philibert (1979) is still part and parcel of the current thinking and subsequent practice of some aged care professionals "the aged feared, despised and discriminated against by the many, looked on as a different species, a minority group, a target population, to be cared for, controlled, segregated and investigated" (pp. 384-385). Likewise, the current Australian undertaking of 
a Royal Commission into Aged Care Quality and Safety resulting from disturbing cases of elder abuse and non-compliance to quality care may need to address what Fahey and Holstein (1993) identified as "society's inability to give meaning to frailty or finitude have exiled the old, privatized their significant life events, and rendered the passage beyond liminality, from marginalization to centrality, particularly difficult". (p. 249)

Surely, there is a need to foster a sense of 'compassionate connectedness' between members of mainstream society $[U s]$ and those who require residential aged care services [Them]. The worth of a human life is validated when those in a position to do so, make the conscious effort to understand and work with the total person-the soma and the psyche. Those older people living the remainder of their life in a residential aged care facility are in no less need for such attention. The foundation for the delivery of humanistic care stems from the linking of humility with vulnerability. The preceding linkage aligns well with the stance taken by the French Philosopher Emmanuel Levinas who challenged us to encounter the other person's face. De Hennezel (2010) explains:

It is a face that overwhelms us with its nudity, arouses in us a sense of infinite responsibility. For, unless we are perverted or mad, how could we not protect someone who, in their extreme weakness, abandons themselves to our hands? (p. 249)

\section{A Question of Suitability to Work in Residential Aged Care}

The Productivity Commission (2008) in a report on trends in aged care services in Australia highlights that "increased longevity is associated with the increased prevalence of co-morbidity (people living with two or more diseases at the same time). This changing pattern of disease is creating greater diversity in the care needs of older people. Further, among the 'old old', it is giving rise to new challenges in caring for frailer people with more complex and demanding care needs" (p. 44). The preceding trend has obvious implications for future workforce planning within the aged care sector, particularly in the case of residential aged care facilities. Deloitte Access Economics (2016) in an examination of Australia's aged care sector indicate "There is an increasing demand for a more highly skilled aged care workforce as older Australians enter residential care at later stages and with more complex medical conditions and comorbidity" (p. 32). While stating the obvious, it still needs to be up front when recruiting staff to work in residential aged care environments - staff alone and collectively have a powerful influence on the lived experiences, wellbeing and quality of life outcomes of aged care recipients. Gawande (2015) makes the point "If to be human is to be limited, then the role of caring professions and institutions - from surgeons to nursing homes - ought to be aiding people in their struggle with those limits" (p. 260). An important dimension of quality aged care is the degree to which staff at all levels are able and willing to initiate meaningful engagement with aged care residents. This means, that despite older people requiring high support needs their overall humanity remains sacrosanct. McCallum (2019) in a witness statement to the Australian Royal Commission into Aged Care Quality and Safety listed the following concerns in relation to residential aged care a) residents suffering undue stress at end of life b) insufficient and non-nutritious food provision and c) incompetent and dangerous medication management. In a separate submission to the Royal Commission into Aged Care Quality and Safety the Victorian Healthcare Association (2019) in reference to residential aged care noted current deficiencies in palliative care competencies and end of life care as well as stating:

Residential aged care providers must be enabled to deliver holistic, multidisciplinary care that is flexible and meets the changing needs of residents. Achieving this will take collaboration across systems, and require governments to work together to remove barriers for health professionals and incentivise the delivery of services including for GPs, palliative care specialists, geriatricians and allied health professionals. (p. 9)

Work by Lloyd et al. (2014) on the maintenance of older persons' dignity and identity report that accounts given by older participants "reveal a great deal about the physical, mental and emotional effort entailed in maintaining a sense of self and highlight the essential role played by social relationships in the maintenance of identity" (p. 1). Irrespective of the models of care deployed in residential aged care there remains the non-negotiable belief that older adults with dementia related disorders continue to maintain personhood and relevance as a social being and that all approaches to care provision and support should reflect this humane view (Higgs \& Gilleard, 2017). Gilster, Boltz and Dalessandro (2017) argue that any serious attempt to implement person centered care, particularly with people suffering from dementia, must first and foremost make a genuine effort to 'know the person'. The preceding authors make the point: "The use of life history or stories may influence the ability of staff to see the whole person, as a human being with a rich history and life versus an individual with dementia who is difficult to care for and time consuming" (p. 111). Ekman et al. (2011) explains "Person-centered care highlights the importance of knowing the person behind the patient - as a human being with reason, will, feelings, and needs - in order to engage the person as an active partner in his/her care and treatment" (p. 2). Miles and Asbridge (2018) provide an important challenge to the residential aged care sector when they point out that 
"person-centered change within care systems has remained largely underexplored, if not, by default, disallowed" (p. 1). All too often, meaningful interaction of staff with older residents is easily avoided by way of the all too common arguments that busy schedules and staffing shortages simply make it difficult to achieve quality relationships. Henderson et al. (2017) drawing upon a review of the literature on missed or rationed care in residential aged care report on a Canadian study by Kalisch (2006) who identified seven reasons for missed care "too few staff (labour resource), time required for a nursing intervention, poor use of existing staff resources, it's not my job syndrome, ineffective delegation, habit, and denial" (p. 416). The preceding researchers also explored the perceptions of nurses and personal care assistants (PCAs) across three Australian states (New South Wales, South Australia and Victoria) on the frequency and causes of missed care in residential aged care. Their findings indicated that "The primary reasons for missed care are staffing shortages and difficulties in meeting residents' complex health care needs due to demands arising from increased resident acuity and fewer skilled nurses to meet this demand" (p. 411). Obviously, the presence or otherwise of teamwork will impact the extent of missed calls for assistance (see Kalisch \& Lee, 2010). Wallis et al. (2016) in an Australian based study involving seven (7) national focus groups of nurses working in residential aged care reported the following key findings:

1) Staffing levels in Residential Aged Care are currently not sufficient to ensure safe, quality aged care;

2) Current skills mix does not address the increasing complexity and acuity of residents in Residential Aged Care and leads to missed care;

3) An evidence based methodology is needed; and that

4) The principles underpinning the methodology tested in this study are appropriate for Residential Aged Care. (p. 99)

The need for an agile residential aged care sector in Australia will become more apparent as increasing numbers of older people in later life seek entry into residential care with a complex and demanding mix of medical conditions and comorbidity. Deloitte Economics (2016) indicate that following consultations with a range of providers of residential aged care "that admitting residents with higher care needs on average means providers need to upskill their workforce" (p. 32). Deloitte Economics also suggest that aged care providers should endeavor to not only attract qualified workers but take the necessary actions to retain and upskill their workforce in accordance with the evolving nature of aged care service and support. It has to be recognized and accepted by policy and key decision makers that population aging and future demand for quality long-term care will have implications for workforce recruitment and skills requirements. Increasing advances in medicine, nursing practice, social work and gerontology along with overall older patient care will mean continuing training and skills development will be necessary across the whole aged care workforce including residential aged care. Galinsky (2007) drawing upon the case of Israel alerts us to the Iceberg Phenomenon that emphasizes the new demands and educational challenges facing the care of older people. Galinsky argues that with the large increase of people over the age of eighty that "Current programs of formal education are not prepared to meet this challenge. Universities at a pregraduate level and postgraduate courses for physicians, nurses, and social workers should be carefully reviewed considering todays shifting attitudes toward the care for the elderly" (p. 60). De Hennezel (2010) makes a case for the benefits of establishing humane care through "an approach that respects the pace of life, and the sensitivity and dignity of the elderly, are obvious. When this approach is taken, many problems disappear-notably, patient agitation, for example- and fewer tranquillisers are prescribed" (p. 112). The reality for people seeking employment in residential aged care is made crystal clear by The President's Council on Bioethics (2005) and should be well and truly upfront as part of employment expectations and responsibilities during the pre-employment interview process:

Good will and good character alone do not make willing caregivers into good caregivers, however. Competence also matters a great deal - not only for doctors, nurses, and other caregiving professionals, but also for volunteer family caregivers who must learn how to care well in matters small and large. It requires learning how to prevent bedsores; how to bathe frail and often resistant individuals without causing accidents; how to navigate the complicated and sometimes unsupportive health care bureaucracy; how to maintain important yet difficult daily routines. (p. 98)

\section{Leadership of the Right Kind: A Must for Humanistic Care}

Australian healthcare professionals Jeon, Merlyn, Sansori and Glasgow (2008) in face to face meetings with experts on aged care and leadership in the United Kingdom report that they received unequivocal support for the "idea of an urgent need to develop a leadership and management program that is residential aged care specific in Australia" (p. 11). Yun-Hee, Merlyn and Chenoweth (2016) argue that "Organisational investment in improving leadership and management skills and capabilities can only improve outcomes for staff stability and productivity, 
care quality and budgets, and better prepare the aged care sector" (p. 54). The longstanding practice of simply 'parachuting' personnel into leadership and managerial positions in aged care is no longer tenable. Dewar et al. (2017) offer approaches that develop transformational leadership that foster emotional, educational and cultural changes as part of enhancing quality improvement in nursing homes.

It is well known that emotional intelligence plays an important part in establishing positive human relationships. According to Carragher and Gormley (2017) "The concepts of emotional intelligence and emotional-social intelligence have emerged as important factors for effective leadership in the healthcare professions" (p. 85). In trying to understand emotional intelligence it is useful to reflect on aspects of work undertaken by Goleman (2001) who claims that high levels of intelligence may not always predict success. According to Goleman one of the factors that help to explain why some individuals with average intelligence can display successful interactions with people is due to what he terms the presence of emotional intelligence. According to Salovey and Mayer (1990) emotional intelligence "involves the ability to monitor one's own and others' feelings and emotions to discriminate among them and to use this information to guide one's thinking and actions" (p. 189). Salovey and Mayer also believe that people with emotional intelligence have a positive measure of mental health due to their awareness of their own feelings and those of others with whom they have regular contact. Barling, Slater and Kelloway (2000) based upon their review of work undertaken by Salovey and Maher (1990) and Goleman (1995) list the following five characteristics that comprise emotional intelligence:

1) understanding one's emotions;

2) knowing how to manage them;

3) emotional self-control, which includes the ability to delay gratification;

4) understanding others' emotions, or empathy; and

5) managing relationships.

The nursing literature is now acknowledging the value of emotional intelligence in nursing work with value added outcomes in terms of nurse leadership roles and nurse-patient relationships. McQueen (2004) a strong advocate for emotional intelligence as part of nursing work puts the case for promoting "The link between emotional intelligence and emotional labour as a fruitful area for further research" (p. 101). Goleman (1996) predicted that future development of organizational teams will increasingly value emotional intelligence as a "workplace asset in the years to come" (pp.159-160). Selecting nurse leaders with a demonstrated level of competence in emotional intelligence to lead the overall operations in residential age care facilities is without question a key component in the planning and delivery of quality based care. The delivery of quality aged care should not be held ransom to laissez faire type leadership that displays a tendency toward delayed decision making and an unremitting allegiance to maintaining the status quo. On the other hand, emotionally intelligent leadership is action oriented as well as promoting the well-being of staff and aged care residents alike. Prezerakos (2018) offers an important challenge for the nursing profession which has major implications for the delivery of humanistic care:

It is necessary for nurses to improve their social and emotional skills because of the particular nature of the nursing profession, which places the healthy or weak person at its center. (p. 86)

\section{Enough Is Enough: Time for Urgent Change}

The medical, nursing, social work and gerontological literature is replete with a litany of paid lip service to the relevance of enhancing the quality of aged care, however, there is no escaping the fact that the humane art of managing and caring for old age in residential care is yet to be fully developed. A recent report by the Australian Gerontology Association (2019) on aged care workforce issues in rural and remote Australia is particularly challenging for residential aged care with implications for concerted "actions to address aged care workforce supply and quality across Australia generally, in rural and remote areas more specifically, and in remote Aboriginal and Torres Strait Islander communities, which have their own unique circumstances and needs" (p. 5). The transformation and change required within aged care, particularly in relation to residential care will depend upon the willingness of governments, professional groups and relevant community organizations to not acquiesce to the status quo but work together to achieve consensus aimed at creating a new future. The challenge confronting transformational change in residential aged care is well articulated by Maddox (1992) "The issue, then, is to explore the limits of the possible". (p. 66)

Residential aged care facilities are in urgent need of committing to a coherent and ethically sustained operational philosophy that supports a) the adoption of quality assurance principles and practices that are part of an evolving and continuous process and b) an approach to care that enables all residents to live all the way to their very end 
with dignity and respect. Without exception, all Quality Assurance Systems should include the management and facilitation of "conversations between relatives and staff; development of ways to give regular two-way feedback about matters concerning the resident and the relationship between staff and relatives; giving staff credit for measures taken to facilitate relatives' involvement in the nursing home care; measures to improve documentation about families' involvement; and working together with minor practical tasks" (Hertzberg \& Ekman, 2000, p. 614). Often in the case of aged care we find it necessary to state the obvious which unfortunately is either deliberately or inadvertently ignored and that is "Respect and kindness are core principles of nursing practice" (Thompson, McClement \& Chochinov, 2011, p. 96). The preceding researchers found sufficient evidence in their research on "How respect and kindness are experienced at the end of life by nursing home residents" that not all family members were confident that their loved one had experienced respect or kindness while in aged care. Russell (2016) makes it clear and simple "The ideal caregiver has a genuine interest in older people...kindness cannot be taught or bought" (p. 30). Genuine aged care involves among other actions the willingness to "listen ethically'. For Gierck (2018) "The opposite to listening is indifference and a painful lack of interest. It's worse than anger. It's a lack of regard for human beings" (p. 30). Listening ethically rests heavily on honest intentions. Without exception, aged care workers should extend to residents the same respect that they wish to receive when the time comes for their turn to speak. At all times, engagement with an older resident should be entered into with an attitude of unconditional positive regard. Impatience or condescension have no place in overall care practices. The right kind of care requires a balanced mix of patience and humility. An important caveat for those who are employed in the care of older people is offered by Quinn (1987):

$\{N]$ ever begin a sentence with "The elderly are" or "the elderly do". No matter what you are discussing, some are not; some do, and some do not. The most important characteristic of the aged is their diversity. The average can be very deceptive, because it ignores the tremendous dispersion around it. Beware of the mean. (p. 64)

\section{Epilogue}

In closing, it must be acknowledged that there are people in the medical and nursing professions along with other personnel across human support services including the wider community who are genuinely committed to enhancing the delivery of an 'ethics of care' approach for the diverse range of older people residing in residential aged care environments. However, despite the commendable work of "frontline staff in homes for the aged, palliative care experts, hospice workers, nursing home reformers and contrarians" (Gawande, 2015, p. 280) there remains much work to be done throughout the aged care sector. In particular, there has been a longstanding reluctance to genuinely examine the life and experiences of older people in residential care facilities including serious exploratory undertakings to determine the staffing mix most suitable for the planning and safe delivery of humanistic care.

An important first step in overcoming the many shortfalls in the care of older people in residential aged care is to "highlight the need for dignity and well-being, and organising the older person's daily life so that they perceive it as meaningful" (James, Bloomberg \& Kihlgren, 2014, p. 1). This means that we need to shed light on the myriad of bad practices and abuses that currently rob older residents of their basic human rights. The delivery of aged care should be overwhelmingly constructed on a teamwork practice approach that is committed to the provision of a sustainable and non-negotiable measure of just, humane, timely and respectful care. No longer can premature or preventable deaths or abuse of nursing home residents resulting from outright neglect or system based failures of one kind or another be tolerated - change has to happen now. De Beauvoir (1977) articulates quite clearly the difficulties confronting the life of older people living in institutional settings "It is quite hard enough to remain a human being when everything, health, memory, possessions, standing and authority have been taken from you" (p. 540). Fahey and Holstein (1993) provide an additional perspective that requires the older person to existentially recognize at least in part, that the "period in which the time remaining is distinctly shorter than the time past" (p. 245). This is why every effort should be made by all people assigned to care for older people to commit to the maintenance of their dignity and respect in a time of such loss and deprivation. Every effort should be made to attack the dangerous and inhumane assumption that "debility and dependence rule out autonomy" (Gawande, 2015, p. 147). Just as any fragile and precious parcel in postal service transit is marked 'Handle with Care' so it should be with any older person who enters a residential aged care facility.

The provision of humanistic care throughout the residential aged care sector can only be achieved if there is a fundamental rethink of the way the workforce is prepared and supported for this environment. May the winds for transformational change of the residential aged care sector blow ever harder, in the hope of ensuring that the policy environment is attuned to facilitating and coordinating collaborative partnerships between industry, vocational, higher education and research institutions with the mandate to prepare a highly skilled aged care workforce 
committed to the ongoing provision of high quality care (Deloitte Access, Economics, 2016). A substantive philosophy for the operation of residential aged care is urgently required that is first and foremost grounded on a strong and genuine sentiment of human kindness, respect and compassion in all relationships with aged care residents. Baas \& Phillipson (2014) remind us all "The quality of a society, however, can also be determined by the way it cares for the most vulnerable; even existential limitations that cannot be removed require meaningful responses" (p. 26). Without exception, those residential aged care providers who are not prepared to employ the right composition of staff with the necessary skill sets should not be allowed to operate a residential aged care facility (see Hyer et al; 2011; Zhang et al; 2006).

Unless Australia has the political will to introduce bold and humanistic reforms in the residential aged care sector, then assuredly the care, safety and dignity of vulnerable older people will remain hostage to the luck of the draw. Failure to undertake transformational change in the residential aged care sector will only heighten the risk of Australia being recognized as a nation that sees "the elderly as a by-product of life with rapidly diminishing value" (Coulter, 2014, p. 2). Although one's life experiences undergo dramatic change upon entry to residential aged care there remains the ever-present mandate for formal caregivers to not stray from 'an ethics of care' when attending to relationships with older people under their care. Katz et al. (2011) draw attention to the stark reality of humankind "Old age is not about 'them': it is about us" (p. 66). In the end, the true art of caring for older people requiring residential care is fostered by caregivers who have well entrenched humanitarian values and an unwavering commitment to human rights as advocated by Ray (2014):

A critical perspective in practice with older people would reasonably place a greater emphasis on human rights perspectives as a means to guide appropriate actions to challenge aged-based discrimination and to promote the commitment that older people with high support needs have the right to personhood and citizenship being upheld, supported and defended. (p. 149)

\section{References}

Allard, T. (2016). Nursing home profits soar as patient care declines. Sydney Morning Herald, 1 January 2016. Retrieved from http://www.smh.com.au/federal-politics/political-news/nursing-home-profits-soar-as-patient-care-declines-2 0151224-glupug.html

Australian Association of Gerontology. (2019). Aged care workforce issues in rural and remote Australia. Melbourne: Australian Association of Gerontology.

Avorn, J. L. (1986). Medicine, health, and the geriatric transformation. Journal of the American Academy of Arts and Sciences, 115(1), 211-225.

Baas, J., \& Phillipson, C. (2014). Connecting meaning with social structure: Theoretical foundations. In J. Baas, J. Dohmen, A. Grenier \& C. Phillipson (Eds.), Ageing, meaning and social structure: Connecting critical and humanistic gerontology. Bristol, UK: Polity Press. https://doi.org/10.1332/policypress/9781447300908.001.0001

Baldwin, R., Chenoweth, L., \& Dela Rama, M. (2015). Residential aged care policy in Australia: Are we learning from evidence?. Australian Journal of Public Administration, 74(2), 128-141. https://doi.org/10.1111/1467-8500.12131

Barling, J., Slater, F., \& Kelloway, F. K. (2000). Transformational leadership and emotional intelligence: An exploratory study. Leadership \& Organization Development Journal, 21(3), 157-161. https://doi.org/10.1108/01437730010325040

Brennan, D., Cass, B., Himelweit, S., \& Szebehely, M. (2012). The marketisation of care: Rationales and consequences in nordic and liberal care regimes. Journal of European Social Policy, 22(4), 377-391. https://doi.org/10.1177/0958928712449772

Brown, B. (2013). Daring greatly: How the courage to be vulnerable transforms the way we live, love, parent and lead. London: Portfolio Penguin.

Buber, M. (2000). I and thou (Trans. Ronald Gregor Smith). New York: Simon \& Schuster.

Carragher, J., \& Gormley, K. (2017). Leadership and emotional intelligence in nursing and midwifery education and practice: A discussion paper Journal of Advanced Nursing, 73(1), 85-96. https://doi.org/10.1111/jan.13141

Coulter, J. (2014). Beyond residential aged care: Restoring value in in ageing. Journal of the National Centre for Sustainability, 1(2), 1-9. 
De Beauvoir, S. (1977). Old age. Ringwood, Victoria, Australia: Penguin Books.

De Hennezel, M. (2010). The warmth of the heart prevents your body from rusting: Ageing without growing old. Melbourne: Scribe Publications.

Deloitte Access Economics. (2016). Australia's aged care sector: Economic contribution and future directions. Dickson, ACT: Aged Care Guild.

Dewar, B., Barrie, K., Sharp, C., \& Meyer, J. (2017). Implementation of a complex intervention to support leadership development in nursing homes: A multimethod participatory study. Journal of Applied Gerontology, 38(7), 931-958. https://doi.org/10.1177/0733464817705957

Ekman, I., Swedberg, K., Taft, C., Lindseth, A; Norberg, A; Brink, E., ... Sunnerhagen, K. (2011). Person centered care: Ready for prime time. European Journal of Cardiovascular Nursing. https://doi.org/10.1016/j.ejcnurse.2011.06.008

Fahey, C. J., \& Holstein, M. (1993). Toward a philosophy of the third age. In T. Cole, A. Achenbaum, P. Jakobi, \& R. Kastenbaum (Eds.), Voices and visions of aging: Toward a critical gerontology. New York: Springer Publishing Company.

Galinsky, D. (2007). New demands on education and training for the care of old people: The case of Israel. In S. Carmel, C. Morse, \& F. Torres-Gil (Eds.), Lessons on aging from three nations (Volume 2: 'The art of caring for older adults'). Amityville, New York: Baywood Publishing Company, Inc.

Gawande, A. (2015). Being mortal: Illness, medicine, and what matters in the end. London: Profile Books Ltd.

Gierck, M. (2018, January 6). Take your time to really hear others. The Age, 30.

Gilster, S., Boltz, M., \& Dalessandro, J. (2017). Long-term care workforce issues: Practice principles for quality dementia care. The Gerontologist, 58(1), S103-S113. https://doi.org/10.1093/geront/gnx174

Goleman, D. (1995). Emotional intelligence: Why it can matter more than IQ. New York: Bantam.

Goleman, D. (1996). Emotional intelligence. London: Bloomsbury

Goleman, D. (2001). An ei-based theory of performance. In C. Cherniss, \& D. Goleman (Eds.), The emotionally intelligent workplace: How to select for, measure, and improve emotional intelligence in individuals, groups and organizations. San Francisco: Jossey Bass.

Grenier, A., \& Phillipson, C. (2014). Rethinking agency in later life: Structural and interpretative approaches. In J. Bass, J. Dohmen, A. Grenier \& C. Phillipson (Eds.), Ageing, meaning and social structure: Connecting critical and humanistic gerontology. Bristol, UK: Polity Press. https://doi.org/10.1332/policypress/9781447300908.003.0004

Groves, A., Thomson, D., McKellar, D., \& Procter N. (2017). The Oakden Report. Adelaide, South Australia: South Australian Health, Department for Health and Ageing.

Henderson, J., Willis, E., Xiao, L., \& Blackman, I. (2017). Missed care in residential aged care in Australia: An exploratory study. Collegian, 24(5), 411-416. https://doi.org/10.1016/j.colegn.2016.09.001

Hertzberg, A., \& Ekman, S. (2000). We, not them and us? Views on the relationships and interactions between staff and relatives of older people permanently living in nursing homes. Journal of Advanced Nursing, 31(3), 614-622. https://doi.org/10.1046/j.1365-2648.2000.01317.x

Higgs, P., \& Gilleard, C. (2017). Ageing, dementia, and the social mind. Hoboken, NJ: Wiley Blackwell. https://doi.org/10.1002/9781119397984

Hillen, J., Vitry, A., \& Caughey, G. (2015). Evaluating medication-related quality care in Australia: A role for collaborative health services. Journal of Pharmacy Practice and Research, 47(1), 63-66. https://doi.org/10.1002/jppr.1320

Hillman, J. (1999). The force of character: And the lasting life. New York: Ballantine Books.

Hyer, K., Thomas, K., Branch, L., Harman, J., Johnson, C., \& Weech-Maldonado, R. (2011). The influence of nurse staffing levels on quality of care in nursing homes. The Gerontologist, 51(5), 610-616. https://doi.org/10.1093/geront/gnr050

Ireland, G. (1996). Aging well with fewer medications. American Behavioral Scientist, 39(3), 306-316. https://doi.org/10.1177/0002764296039003007

James, I., Blomberg, K., \& Kihlgren, A. (2014). A meaningful daily life in nursing homes - a place of shelter and 
a space of freedom: A participatory appreciative action reflection study. BMC Nursing, $13,19$. https://doi.org/10.1186/1472-6955-13-19

Jecker, N. (1993). Justice and mother love: Toward a critical theory of justice between old and Young. In T. Cole, A. Achenbaum, P. Jakobi, \& R. Kastenbaum (Eds.), Voices and visions of aging: Toward a critical gerontology. New York: Springer Publishing Company.

Jeon, Y., Merlyn, T., Sansori, F., \& Glasgow, N. (2008). Optimising the residential aged care workforce: Leadership and management study. Canberra, ACT: Australian Primary Health care institute-ANU College of Medicine, Biology \& Environment.

Kalisch, B. (2006). Missed nursing care: A qualitative study. Journal of Nursing Care Quality, 21(4), $306-313$. https://doi.org/10.1097/00001786-200610000-00006

Kalisch, B., \& Lee, K. H. (2010). The impact of teamwork on missed nursing care. Nursing Outlook, 58, $233-241$. https://doi.org/10.1016/j.outlook.2010.06.004

Katz, J., Holland, C., Pearce, S., \& Taylor, E. (2011). A better life: What older people with high support needs value. Cambridge, UK: Joseph Rowntree Foundation.

Koper, D., Kamenski, G., Flamm, M., Böhmdorfer, B., \& Sönnichsen, A. (2013). Frequency of medication errors in primary care patients with polypharmacy. Family Practice, 30(3), 313-319. https://doi.org/10.1093/fampra/cms070

Lloyd, L., Calnan, M., Cameron, A., \& Seymour, J. (2014). Identity in the fourth age: Perseverance, adaptation and maintaining dignity. Ageing \& Society, 34(1), 1-19. https://doi.org/10.1017/S0144686X12000761

Maddox, G. (1992). Aging and well-being. In N. Cutler, D. Gregg, \& M. Lawton (Eds.), Aging, money, and life satisfaction: Aspects of financial gerontology. New York: Springer Publishing Company.

McCallum, J. (2019). Witness statement: Royal commission into aged care quality and safety. Brisbane, Queensland: National Seniors Australia.

McQueen, A. C. (2004). Emotional intelligence in nursing work. Journal of Advanced Nursing, 47(1), $101-108$. https://doi.org/10.1111/j.1365-2648.2004.03069.x

Miles, A., \& Asbridge, J. (2018). Person centeredness in health and social care: What exactly is it that patients and their carers want?. European Journal for Person Centered Healthcare, 6(1), 1-4. https://doi.org/10.5750/ejpch.v6i1.1569

Philibert, M. (1979). Philosophical approach to gerontology. In J. Hendricks, \& C. D. Hendricks (Eds.), Dimension of aging (pp. 379-394). Cambridge, MA: Winthrop.

Prezerakos, P. (2018). Nurse managers' emotional intelligence and effective leadership: A review of the current evidence. The Open Nursing Journal, 12, 86-92. https://doi.org/10.2174/1874434601812010086

Productivity Commission. (2008). Trends in aged care: Some implications (Commission Research Paper). Canberra: Productivity Commission.

Quinn, J. (1987). Attitudes of professionals toward the aged. In G. Maddox (Ed.), The Encyclopaedia of Aging. New York: Springer.

Ray, M. (2014). Critical perspectives on social work with older people. In J. Bass, J. Dohmen, A. Grenier, \& C. Phillipson (Eds.), Ageing, meaning and social structure: Connecting critical and humanistic gerontology. Bristol, UK: Polity Press. https://doi.org/10.1332/policypress/9781447300908.003.0008

Russell, S. (2016, January 9). Aged-care gravy train. The Age, 30.

Salovey, P., \& Mayer, J. (1990). Emotional intelligence. New York: Baywood Publishing. https://doi.org/10.2190/DUGG-P24E-52WK-6CDG

The President's Council on Bioethics. (2005). Taking care: Ethical caregiving in our aging society. Washington, DC: The President's Council on Bioethics.

The South Australian Government. (2017). Response to the Oakden older persons mental health service. Adelaide: South Australian Government.

Thompson, G., McClement, S., \& Chochinov, H. (2011). How respect and kindness are experienced at the end of life by nursing home residents. Canadian Journal of Nursing Research, 43(3), 96-118.

Townsend, P. (2007). Using human rights to defeat ageism: Dealing with policy-induced 
“structural-dependency". In M. Bernard, \& T. Scharf (Eds.), Critical perspectives on ageing societies. Bristol, UK: The Policy Press. https://doi.org/10.1332/policypress/9781861348906.003.0003

Victorian Healthcare Association. (2019). Submission: Royal commission into aged care quality and safety. Melbourne: Victorian Healthcare Association.

Willis, E., Price, K., Bonner, R., Henderson, J., Gibson, T; Hurley, J., ... Currie, J. (2016). Meeting resident care needs: A study of the requirement for nursing and personal care staff. Canberra, ACT: Australian Nursing and Midwifery Federation.

Yun-Hee, J., Merlyn, T., \& Chenoweth, L. (2010). Leadership and management in the aged care sector: A narrative synthesis. Australasian Journal on Ageing, 29(2), 54-60. https://doi.org/10.1111/j.1741-6612.2010.00426.x

Zhang, N., Unrah, L., Lui, R, \& Wan, T. (2006). Minimum nurse staffing ratios for nursing homes. Nursing Economics, 24(2), 78-85, 93.

\section{Copyrights}

Copyright for this article is retained by the author(s), with first publication rights granted to the journal.

This is an open-access article distributed under the terms and conditions of the Creative Commons Attribution license (http://creativecommons.org/licenses/by/4.0/). 